\title{
Dinâmicas de gênero e migração: jovens mulheres rurais e esvaziamento do campo no norte de Minas Gerais
}

\author{
Gender and migration dynamics: young rural women and seizing the field \\ in the North of Minas Gerais
}

Deborah Dias Pereira

Jaqueline da Silva Teixeira

Ana Paula Glinfskói Thé

Andréa Maria Narciso de Paula

Universidade Estadual de Montes Claros - UNIMONTES - Montes Claros - Minas Gerais - Brasil

Resumo: O êxodo rural brasileiro compreendeu um processo de grande magnitude desde o seu início, onde, em comparativo, poucos países experimentaram fluxo migratório tão intenso, tendo em vista a quantidade absoluta da população atingida. Uma das características encontradas nos movimentos migratórios brasileiros se estabelece na diferenciação por sexo. Estudos apontam que as mulheres migram mais do que os homens, além do fluxo migratório se caracterizar cada vez mais pela saída de jovens do campo. Nesse sentido, o presente artigo se propõe a analisar a categoria rural, abordando a situação das mulheres migrantes no contexto do Norte de Minas. Para tanto, utilizará do levantamento bibliográfico na construção de uma revisão acerca das práticas migratórias do campo realizadas por jovens, de modo a entender e problematizar a questão do gênero no processo migratório. Como resultado parcial temse que as mulheres continuam migrando, sendo tal deslocamento realizado com propósitos variados e, muitas vezes, devido à ausência de políticas públicas regionais, que resultam em pouca perspectiva de valorização do campo/gênero. Sendo assim, o processo migratório, principalmente no que diz respeito à questão de gênero, não se encerra nas discussões apresentadas, sendo necessários estudos que acompanhem as distintas dimensões que o migrar implica.

Palavras-Chave: Gênero. Migração. Norte de Minas.

\begin{abstract}
:
The brazilian rural exodus comprised a process of great magnitude since its beginning, where, comparatively, few countries experienced such an intense migratory flow, given the absolute amount of the population reached. One of the characteristics found in the brazilian migratory movements is established in the differentiation by sex. Studies show that women migrate more than men, besides the migratory flow is characterized more and more by the exit of young people from the countryside. In this sense, the present article proposes to analyze the rural category, addressing the situation of migrant women in the context of North Mines. To do so, it will use the bibliographical survey in the construction of a review about the field migrations carried out by young people, in order to understand and problematize the question of gender in the migratory process. As a partial result, women continue to migrate, such displacement being carried out for a variety of purposes and, often, due to the absence of regional public policies, which result in little prospect of valorization of the field / gender. Thus, the migratory process, especially with regard to the gender issue, does not end in the discussions presented, and studies are necessary to accompany the different dimensions that migrate implies.
\end{abstract}

Keywords: Gender. Migration. North of Minas. 


\section{Introdução}

O êxodo rural brasileiro compreendeu um processo de grande magnitude desde o seu início, onde, em comparativo, poucos países experimentaram fluxo migratório tão intenso, tendo em vista a quantidade absoluta da população atingida, como o processo engendrado no Brasil. Nesse sentido, os movimentos de migração equiparam-se ao denominado "esvaziamento da população rural" considerando-se o amplo movimento de desruralização que forneceram um volume populacional considerável para as áreas urbanas. Porém não se pode tomar esse "esvaziamento" como realidade única do rural, sendo este um espaço permeado por dinâmicas próprias, e continuamente interligado com o urbano (CAMARANO; ABRAMOVAY, 1999, p. 2; ABROMOVAY, 2000).

Mais especificamente em relação ao estado de Minas Gerais, seu processo histórico denota forte presença da migração, perpassando pelo ciclo da mineração com a "descoberta das minas"; a produção do café, além do denominado "caminho do gado", dentre outras etapas que se constituíram enquanto momentos de elevados fluxos populacionais (FONSECA; GUIMARÃES; FERNANDES, 2014, p. 90).

Uma das características encontrada nos movimentos migratórios brasileiros se estabelece na diferenciação por sexo. Tal fato incorre em aumento proporcional e contínuo da presença masculina nos espaços rurais, o processo chamado "masculinização do rural" (CAMARANO; ABRAMOVAY, 1999).

Os fluxos de migração dizem do deslocamento para os centros urbanos de famílias inteiras de agricultores, especialmente da população jovem. Os dados do Instituto de Pesquisa Econômica Aplicada - IPEA (1999), apontam que as mulheres são a maioria do público que abandona o campo, muitas vezes motivadas pela busca de empregos nas cidades, tanto em empresas quanto no trabalho em residências, enquanto domésticas e diaristas (HARTWIG, 2012).

De acordo com pesquisas de Camarano e Abramovay (1999), as mulheres migram mais do que os homens, além do fluxo migratório se caracterizar cada vez mais pela saída de jovens do campo. Faria; Macedo e Paula (2014) corroboram com tal ideia ao afirmarem que as migrações femininas, embora permanentemente negligenciadas, possuem como porta de entrada e socialização nas cidades o trabalho doméstico.

Abordando com mais especificidade a negligência em relação aos estudos sobre as mulheres do campo, Ellen Woortman (2010) descreve que as pesquisas prévias tinham por foco a dinâmica da família camponesa e as relações aí engendradas. Hoje a categoria feminino possui espaço de inserção enquanto objeto de estudo definido, permeado pelos papéis, contextos e caracteres simbólicos particulares. Contudo, apesar dos avanços produzidos e elencados, tem-se que os estudos de gênero dentro do universo rural ainda se adjetivam como insipientes, apontando este espaço como uma relevante via de consolidação.

A autora, ao detalhar os avanços, aponta que para além dos estudos acerca da preservação dos conhecimentos tradicionais, do potencial produtivo das mulheres, da incorporação de novas técnicas e manejos em suas atividades; existe atualmente espaço para que se trabalhe as questões de saúde, o papel exercido mediante a renda obtida, modalidades inéditas de trabalho, a lida com os benefícios ou capital complementar, bem como o dilema enfrentado entre deixar ou não o lugar de moradia tendo em vista todas as peculiaridades que a migração provoca (WOORTMAN, 2010).

Qualquer que seja o local de atuação profissional ou mesmo residência, todo sujeito vive em um mundo atravessado por culturas que, baseadas em mecanismos simbólicos, conferem certas características específicas, diferenciais e 
dinâmicas a homens, mulheres, crianças, jovens, adultos e anciãos. As estratégias utilizadas para moldar e disciplinar atores e atrizes sociais se estabelecem, de forma direta ou não, no campo das normativas de gênero, onde os paradigmas diversos são destinados a subsidiar a ação regulamentadora, as legislações, políticas, etc. (SCOTT, 2010).

Nesse sentido, o presente artigo se propõe a esmiuçar o diálogo oferecido pelo marcador do rural, abordando a situação das mulheres migrantes neste contexto. Para tanto, utilizará do levantamento bibliográfico na construção de uma revisão acerca das práticas migratórias do campo realizado por jovens, de modo a entender $e$ problematizar a questão do gênero no processo migrante.

\section{A questão rural-urbano}

A discussão sobre as categorias rural e urbano é permeada por distintos pontos de vista, e acompanha as mudanças que prevalecem em tais espaços. De acordo com Abramovay (2000), a definição não deve englobar apenas aspectos relacionados aos sistemas de produção, mas sim questões que dizem respeito ao espaço. Um exemplo desse apontamento se deve ao fato de que o rural não envolve apenas setores agrícolas, sendo também constituído por outras atividades.

O autor afirma que o rural não corresponde a um fenômeno a ser superado por meio da urbanização, não se trata de uma linha evolutiva com uma noção equivocada de progresso. Rural e urbano se relacionam constantemente, ambos conferindo importância a tal dinâmica (ABRAMOVAY, 2000).

Como salienta Marques (2002), há definições que levam em consideração apenas o que falta ao espaço rural, ao compará-lo com o urbano, não levando em consideração suas peculiaridades, sendo uma perspectiva que encara o rural e o urbano como um continuum. Trata-se de uma perspectiva que, assim como foi pontuado por Abramovay (2000), coloca o rural como algo a ser ultrapassado pelos processos de urbanização.

Tal abordagem desconsidera o dinamismo que permeia o rural, colocando-o também em posição oposta ao urbano, numa perspectiva dicotômica, que segundo Marques (2002) deve ser substituída para que se considere as relações que estes espaços estabelecem, o que implica inclusive em novas noções de desenvolvimento. Abramovay (2000) também traz essa noção do quanto a mera oposição entre rural e urbano podem impedir que se tenha acesso às novas dinâmicas que permeiam tais espaços.

De acordo com Marques (2002) essas abordagens dicotômicas e de continuum em relação ao urbano-rural, provém de um cientificismo inicial e do desenvolvimento do modo de produção capitalista. A industrialização e a lógica do consumo afetam o rural e o urbano, sendo que os modos de vida desses espaços passam a ser subordinados ao modo de produção vigente. Desse modo, o autor afirma que novos modelos de desenvolvimento sejam pensados não só para o rural, mas também para as cidades, já que em ambos os espaços a classe trabalhadora se vê diante de condições instáveis, o que ocasiona inclusive seu constante deslocamento.

Não se pode, porém, pensar um modelo de desenvolvimento rural baseado nas demandas urbanas, isso seria entrar novamente no continuum que só vê a urbanização como modelo de desenvolvimento, e mantém o rural na condição de subordinação; é preciso que se pense o desenvolvimento a partir da realidade e saberes locais, levando em consideração a dinâmica do território em questão, entendendo que território também engloba as relações estabelecidas continuamente com o urbano (MARQUES, 2012).

Falar em rural-urbano implica então em falar sobre relações. Como é apontado por Gomes 
(2015), a mobilidade socioespacial aumentou significativamente, promovendo o intercâmbio entre os distintos modos de vida, o que leva a uma concepção de espaços híbridos. Segundo a autora, o urbano e o rural não são encarados como extremos, o que reforça as concepções anteriormente citadas, de que não cabe mais uma visão dicotômica ao tratar do assunto.A distinção rural-urbano diz respeito, portanto, à modos de vida, trazendo especificidades no que diz respeito às relações estabelecidas, ultrapassando os espaços ocupados.

Segundo Gomes (2015), as diferenças entre tais modos de vida variam conforme a incidência das dinâmicas globais nas relações, já que a globalização implica em uma flexibilização de fronteiras. Tais fenômenos evidenciam a construção de múltiplas territorialidades, em que distintos modos de vida se mesclam. Haesbaert (2013) aponta a noção de multiterritorialidade, fenômeno que influi diretamente na construção dos modos de vida anteriormente mencionados, onde se sobressaem as interações e flexibilizações territoriais, que são também são frutos das redes de influências.

\section{O sertão do norte de Minas e a migração}

De acordo com Fonseca; Guimarães e Fernandes (2014), o Norte de Minas compreende uma área geográfica de oitenta e nove municípios cuja principal atividade econômica se localiza na agropecuária, excetuando-se os municípios de Montes Claros, Pirapora, Bocaiúva e Várzea da Palma, que possuem tendências industriais. A cidade de Montes Claros possui destaque ao se constituir enquanto pólo centralizador de serviços especializados nas diversas áreas, a exemplo da saúde, educação, finanças, etc., portanto, local de maior atração populacional da mesorregião nortemineira.
Ainda segundo os autores, a mesorregião do Norte de Minas é caracterizada enquanto local permeado pela precarização das condições de trabalho e pobreza. Os municípios da região que se destacaram pela industrialização mais acentuada não obtiveram melhora no quadro de desigualdades sociais a partir do advento tecnológico. Houve sim grande elevação do contingente populacional, com intensificação da migração através da busca de empregos (FONSECA; GUIMARÃES; FERNANDES, 2014).

Conforme o Censo Demográfico 2010, do Instituto Brasileiro de Geografia e Estatística (IBGE), as Unidades de Federação que apresentam uma maior parcela de população natural residindo em outras Unidades são os Estados de Minas Gerais e Bahia, sendo o Estado de São Paulo um dos principais receptores destas populações. Outro ponto de relevância se localiza na quantidade de imigrantes que chegam ao Estado de Minas Gerais, sendo que os imigrantes de retorno também fazem parte deste quadro. Apesar de não possuir destaque em relação a tabela de resultados dos demais Estados, a nível interno tal indicador contribui de modo significativo para uma mudança no saldo migratório.

Pesquisas revelam que as migrações rurais internas também continuam a se fazer no Norte de Minas, principalmente com direção ao interior de São Paulo com vistas ao trabalho nas lavouras de soja, café e cana; bem como a cidades pequenas e médias da região. Tais movimentações reiteram a lógica da modernidade baseada no capital, forçando os trabalhadores a buscarem fora de seus locais de origem oportunidades de emprego (PAULA, 2012a). Ainda de acordo com Paula (2003; 2012b) as migrações intraregionais ganharam destaque no cenário norte-mineiro, sendo a cidade de Montes Claros, uma das principais receptoras desses sujeitos, que passam a migrar não só sazonalmente, mas também com a intenção de fixar 
residência no local, o que revela os diversos nuances dos processos migratórios.

O termo sertão denota uma categoria de bastante relevância e recorrência no pensamento social brasileiro, sendo conhecido desde antes da chegada dos colonizadores portugueses. A história do termo aponta que desde o século XII os lusitanos empregavam a palavra "sertão" ou "certão" de modo a referir-se a regiões localizadas dentro de Portugal, porém distantes de Lisboa. A partir do século $X V$, o vocábulo era usado para nomear áreas amplas, especialmente no interior, sobre as quais não se conhecia muito. Para alguns estudiosos linguistas, “sertão/certão" deriva de "desertão” (AMADO, 1995, p. 145-147).

No cenário do Brasil, sertão historicamente estava atrelado a terras "sem fé, sem lei, sem rei", ou seja, espaços afastados do litoral civilizado, colonizado nos moldes e religiosidade européias. De forma geral, imaginava-se terras habitadas por selvagens, índios sanguinários, animais ferozes, ambos distantes do controle estatal. Litoral e sertão representavam categorias opostas, contraditórias. Tanto para os primeiros colonizadores, passando pelos bandeirantes e depois pelos exploradores de riquezas minerais, "sertão" sempre possuiu significados amplos, todos eles baseados na posição social e espacial do enunciante (AMADO, 1995).

A categoria sertão, conforme descrita poeticamente por Rosa (2006, p. 8-9):

"O senhor tolere, isto é o sertão. Uns querem que não seja! que situado sertão é por os campos-gerais afora a dentro, eles dizem, fim de rumo, terras altas, demais do Urucúia. Toleima. Para os de Corinto e do Curvelo, então, o aqui não é dito sertão? Ah, que tem maior! Lugar sertão se divulga: é onde os pastos carecem de fechos; onde um pode torar dez, quinze léguas, sem topar com casa de morador [...] O gerais corre em volta. Esses gerais são sem tamanho [...] O sertão está em toda a parte".
Conforme endossa Paula (2012), as narrativas e histórias pessoais construídos por homens e mulheres que fazem do sertão "o espaço vivido de suas vidas" (p. 142), são muitas vezes apartados dos discursos da modernidade, da tecnologia e dos saberes hegemônicos. As representações sociais e o imaginário popular demonstram que os saberes tradicionais, práticas de trabalho, ritos e tradições de tais sujeitos sertanejos são pouco respeitados e referenciados pela ciência.

Assim, os camponeses outrora expropriados de suas terras e conduzidos forçosamente para outros espaços são percebidos enquanto simulacro do real, na tentativa caracterizar os conhecimentos e fazeres tradicionais enquanto antigo, velho; algo a ser superado na busca do moderno, do urbano, do tecnológico (PAULA, 2012).

Conforme assegura Cunha (2013) em sua tese de doutoramento, os camponeses do sertão do Norte de Minas utilizam como estratégias de propagação da economia o acionamento do ambiente e da família. Essas duas categorias envolvem a construção de relações sociais permeadas pela hierarquia, ainda que atualmente tais hierarquias possuem ângulos mais sutis. A dinâmica do ambiente e da família apontada pela autora contraria a lógica de se pensar a unidade de produção enquanto separada da unidade de consumo, onde os trabalhos executados obedecem à construção familiar de ordenamento, de estrutura.

Para Paula (2012), as práticas tradicionais podem ser encontradas na identidade, na reciprocidade entre os grupos e famílias, nas comunidades, através da cultura e da transmissão da oralidade que retratam as vivências e experiências desses povos sertanejos.

De acordo com Faria; Macedo e Paula (2014), dentre as condições para a migração rural, tem-se a busca por trabalho e educação. Além disso, a migração engloba outras perspectivas, sendo inclusive um processo que visa de 
manutenção social do grupo familiar. A migração envolve a influência bastante acentuada das experiências de parentes e conhecidos como umas das condições de abandono do rural.

\section{Perspectivas de gênero}

O uso do termo gênero desponta mediante necessidade de rompimento com o determinismo biológico apontado no conceito de sexo. Entendese, portanto, que a chave conceitual gênero diz respeito às marcas simbólicas presentes nas construções culturais das identidades dos indivíduos. As investigações iniciais propostas pelos trabalhos feministas tinham como foco a denúncia da associação do gênero com o sexo biológico, apontando assim a inevitabilidade de se separar as características humanas biológicas (sexo) das características humanas socialmente construídas (gênero). Para as estudiosas de tais conceitos, sexo caracterizava as diferenças morfológicas do aparelho reprodutor, bem como aspectos hormonais e cromossômicos. Nesse sentido, se reconhecia unicamente dois sexos, universais: homem e mulher. Gênero evocava uma criação exclusivamente social, representações e práticas coletivas que interpretavam o que era ser homem ou o que era ser mulher, com base em conjuntos de atributos que ligava a categoria biológica um determinado modo de agir/ser (CASARES, 2014).

Pensar a perspectiva de gênero implica reconhecer que as desigualdades entre homens e mulheres não são naturais ou imutáveis, mas, ao contrário, provém de relações sociais historicamente construídas. A separação efetuada entre os marcadores biológicos e a construção do que se entende comumente como femino conduz à crítica explícita da justificativa da exclusão das mulheres baseadas em razões naturais e não culturais; posição esta que impede mudanças e transformações sociais. Tal "cegueira tradicional", conforme dizer de Aurelia Casares (p. 43), foi a responsável por permitir e naturalizar o poder público e político conferido aos homens, na intenção de manter a ordem social, de acordo com a ideologia patriarcal dominante (CASARES, 2014).

Ellen Wortmann tece uma crítica à academia ao apontar que este espaço se constitui, muitas vezes, enquanto silenciador do ponto de vista feminino, logo, de suas práticas e atuações sociais. A própria ciência antropológica, em suas raízes históricas, referia-se às mulheres, normalmente, em uma parte final dos seus trabalhos, dos seus livros, com estreita ligação ao universo familiar, práticas alimentares e envolvimentos religiosos. Vigorou, por muito tempo, a naturalização da ótica masculina, já que as teorias construídas faziam pouca ou nenhuma menção ao universo feminino (WOORTMAN, 1992; 2010).

Nesse sentido, Casares (2014) discute a preponderância das práticas androcentristas que se afirmavam nas ciências sociais, com destaque para a Antropologia. Para a autora, o androcentrismo se caracteriza como um segmento do etnocentrismo, ou seja, ancora-se na identificação dos valores masculinos como valores da sociedade como um todo. O etnocentrismo, por sua vez, diz respeito ao julgamento dos modos de vida e de organização social e moral de outras comunidades com base na perspectiva da própria sociedade, onde as formas de entendimento do mundo do pesquisador faz com que se tome as diferentes sociedades como anomalias.

A crença na produção científica tida até então como "assexuada, universal e desprendida de qualquer subjetividade", lócus dominado pelos homens, tinha efeitos tanto a coleta de dados quanto a formulação de hipóteses e, em decorrência, os resultados encontrados. O viés androcêntrico contribui, desse modo, para perpetuação de práticas científicas que possuem como ponto de referência os homens (andros), o que leva à consequente invisibilização feminina. Assim, os questionamentos tecidos pelas feministas 
são resumidos abaixo por Aurelia Casares (2014, p. 21-22):

I. O androcentrismo do antropólogo e da antropóloga: se relaciona com a perspectiva particular do (a) pesquisador (a), que traz suposições e conceitos pré-formados acerca das relações homem/mulher para dentro de suas análises;

II. O androcentrismo dos (as) informantes: fator que pode transmitir ao pesquisador um entendimento "viciado" das relações de gênero. Tal fato tende a ocorrer com maior frequência em sociedades onde existe subordinação das mulheres em relação aos homens;

III. O androcentrismo intrínseco à ciência antropológica: liga-se à parcialidade ideológica característica da cultura ocidental, que faz com que os pesquisadores analisem as relações entre homens e mulheres em outras comunidades através do olhar da assimetria presente em sua própria cultura de desigualdade entre os gêneros.

Conforme evidencia os dados do Informe sobre o Desenvolvimento Humano 2016, as desigualdades acerca do desenvolvimento humano, principalmente em grupos específicos, continuam a existir devido à discriminação. As mulheres, por exemplo, são alijadas no que tange às oportunidades. A questão da posse da terra ilustra de maneira bastante clara o exposto: apenas 10 a 20\% dos proprietários de terra nos países em desenvolvimento são mulheres. $\mathrm{Na}$ maioria dos países, as mulheres sofrem discriminação em relação aos bens produtivos, o que incorre em situação de desvantagem (PNUD, 2016).

Para Carmo (2015), ao longo dos anos, as relações no campo, bem como diferentes ramos da sociedade brasileira, foram pesquisados como local de atuação majoritariamente masculino. Logo, os aspectos econômicos, as formas de produção e cultivo, as escolhas do que plantar e quando plantar, os sonhos e as vontades explicitadas, além da violência, do silenciamento e migração obedeceram durante décadas da história apenas a perspectiva do homem "enquanto produtor e gerenciador das relações familiares" (p. 330)

Assim, as mulheres foram olhadas, ao longo da história, enquanto seres que tinham uma atuação limitada, contingenciada no mundo, restritas aos espaços e atividades tidas como naturalmente femininas. As mulheres aparecem reivindicando em espaços como Clube das Mães, nas Comunidades Eclesiais e religiosas, nas reuniões de escolas e creches infantis, nas áreas que demandavam atendimento médico, dentre outras, de modo a expor quais cenários se constituíam enquanto espaços de ação feminina (CARMO, 2015).

Nessa lógica, as mulheres "não existiam para o espaço público". Aquelas que trabalhavam na agricultura ou com artesanato, exercendo um considerável papel econômico, era recenseadas, invisíveis para os mecanismos de organização e controle social, sendo, desse modo, localizadas enquanto domésticas ou auxiliares. "Em suma, as mulheres não contam". (PERROT, 2005, p. 11 apud CARMO, 2015).

De modo a oferecer uma leitura crítica das relações sociais entre os gêneros, Guacira Louro (1997) afirma que tal elemento possui tamanha relevância que passa a contribuir no estabelecimento da identidade dos sujeitos. Ora, o gênero faz parte do indivíduo, constituiu-o. Logo, as variadas instituições, a exemplo da igreja, justiça, escolas, política, etc., que se apresentam nas sociedades são constituídas pelos gêneros ao passo que também constituem, "fabricam" os sujeitos. Assim, os diferentes espaços vividos são atravessados pelos gêneros, produzem e reproduzem tais relações.

Tendo em vista o trabalho rural, historicamente a produção cafeeira ocupou grande mão de obra, especialmente nos estados do Paraná e São Paulo. Assim, famílias inteiras viviam sob regimes de arrendamento, meia, parceria, onde, normalmente, o homem mais velho do grupo familiar 
se responsabilizava pelos contratos estabelecidos. Nesse ínterim, mulheres e homens trabalhavam ombro a ombro para a manutenção do empreendimento do café. Os contratos estabelecidos, de forma natural, consideravam a força de trabalho feminina e infantil enquanto determinantes; e as famílias viam neste uma nova possibilidade de ganho, ultrapassando as rígidas relações do meio rural que eram pactuadas entre atores sociais desiguais (CARMO, 2015).

Conforme apresenta Guacira Louro (1997), o entendimento das desigualdades entre homens e mulheres não pode ser pensado e buscado na biologia, numa perspectiva de demarcação de diferenças. As problematizações devem ser encontradas no interior das relações sociais, tendo a história papel fundamental no entendimento ao acesso e representação das práticas de uma determinada sociedade.

Com tal posicionamento concorda Aurelia Casares (2014), que pontua que a construção da identidade pessoal se encontra bastante atrelada ao gênero, o que faz com que a identidade pessoal de um sujeito e a visão que este possui de si mesmo, bem como os projetos pessoais que elabora ao longo de sua trajetória existencial estejam emparelhados com a educação recebida desde a infância, que define o que é ser mulher e o que é ser homem, com base nos paradigmas sociais.

Consoante a perspectiva de gênero, ao tratar das migrações, Camarano e Abramovay (1999) sugerem que existem três momentos distintos em relação a migração de jovens mulheres do campo para as cidades, a saber:

1) Migrações ligadas à oferta de trabalho no meio urbano, onde a mão de obra feminina arrefece o setor de serviços, estando tal público inserido nas empresas e nas residências;

2) Dinâmicas intrafamiliares constituídas no meio rural, onde as moças, além de uma dura carga de trabalho, possuem pouca perspectiva de valorização que sinalize a permanência no campo;
3) Ligação entre processos migratórios e educação, onde se valoriza mais o estudo das mulheres em detrimento dos homens.

Segundo Faria; Macedo e Paula (2014), os fenômenos migratórios femininos se constituem enquanto um processo amparado por redes sociais, que englobam tanto condições de parentesco, quanto experiências de pessoas conhecidas. Segundo os autores, tais redes possibilitam não só uma ponte com o local destino do migrante, por influenciar a decisão por meio de experiências prévias e informações, como também uma ligação afetiva com o local de origem, por serem o acolhimento e via identitária em meio a um novo contexto de moradia.

De acordo com Paula (2003; 2012) percebese na região do Norte de Minas um aumento no número de mulheres migrantes, tendo entre outras motivações, a busca por uma inserção no mercado de trabalho. Outro situação apresentada pela autora, é a migração de toda a família, que ao invés de ser somente transitória, pode também ser definitiva, tendo Montes Claros como um dos espaços para uma nova luta por sobrevivência.

Faz-se necessário pontuar que em suas vivências relacionais, os sujeitos vão se constituindo enquanto masculino e feminino dado a influência dos diferentes discursos, símbolos, arranjos e lugares sociais, que demarcam modos de ser e de estar no mundo. Contudo, tais construções possuem caráter transitório, estão em contínua transformação ao longo do tempo e dos espaços sociais, tendo em vista os processos históricos, de classe, etnias e singularidades (LOURO, 1997).

Nas análises das migrações existe a necessidade de se considerar que, para além das distinções regionais e históricas, os grande ciclos econômicos, inseridos dentro do contexto nacional, experimentaram ações e desdobramentos dos relacionamentos e ações de homens e mulheres. $\mathrm{O}$ momento histórico vivido comporta dinâmicas singulares, como esclarece Carmo (2015). 


\section{Considerações finais}

A partir dos estudos e levantamentos realizados de modo a construir o presente artigo, evidenciou-se as variáveis que se apresentam quando se trata das dinâmicas migratórias, onde diversas motivações, influências culturais e do meio familiar, além da busca por melhores postos de trabalho, interagem em conjunto com aspectos políticos e históricos, tendo em vista a constituição da região sertaneja do Norte de Minas Gerais.

Tendo em vistas tais variáveis, percebe-se que $\mathrm{o}$ processo migratório envolve diversos nuances e desfechos, sendo atravessado e influenciando por distintos fenômenos sociais. Além disso, a relação urbano-rural perpassa o terreno dicotômico para dar lugar a uma rede de relações que não deve passar despercebida, sendo o processo migratório uma prova de que entre o rural e o urbano há bem mais do que distintos espaços separados. Existe sim, por sua vez, uma interação particular que influi diretamente nos modos de vida e trocas realizadas entre ambos.

As mulheres se apresentam enquanto grupo migrante com índices estatísticos mais elevados, assumindo em sua partida, muitas vezes, um protagonismo que vai além das visões arcaicas que Ihe colocavam como submissa de decisões de outrem. Apesar das mudanças e avanços, a migração trata-se de um fenômeno que carece de atenção por parte da ciência e de políticas públicas, de modo que possibilitem àquelas que migram melhores oportunidades nos seus locais de destino, e àquelas que desejam ficar, melhores condições e alternativas junto ao rural que satisfaçam seus anseios por meio de condições dignas de vida. São necessários estímulos que possam ir ao encontro ao protagonismo que a mulher rural nunca deixou de ter, apesar deste ser desvalorizado durante muitos anos e por diferentes atores sociais.
Nesse sentido, se faz importante o prosseguimento das análises e influências que constituem o universo de possibilidades de abandono do lócus rural, especialmente quando este percurso é realizado por mulheres, considerando que tal categoria abarca relações e práticas singulares em comparação com outros atores sociais. Portanto, entende-se que o esforço aqui empreendido não esgota de forma alguma as análises da temática.

\section{Referências}

ABRAMOVAY, Ricardo. Funções e medidas da ruralidade no desenvolvimento contemporâneo. Rio de Janeiro: IPEA, 2000.

AMADO, Janaína. Região, Sertão, Nação. Estudos Históricos, v. 8. n. 15, p. 145-151, 1995.

CAMARANO, Ana Amélia; ABRAMOVAY, Ricardo. Exodo rural, envelhecimento e masculinização no Brasil: Panorama dos últimos 50 anos. Rio de Janeiro: IPEA, 1999.

CARMO, Maria Andréa Angelotti. Trabalhadoras rurais no Triângulo Mineiro: atuações (in)visíveis. In: MAIA, Cláudia; PUGA, Vera Lúcia (org.). História das mulheres e do gênero em Minas Gerais. Ilha de Santa Catarina: Editora Mulheres, 2015. 552p.

CASARES, Aurelia Martín. Antropología del Género: culturas, mitos y estereotipos sexuales. 2. ed. Madrid, Spain: Ediciones Cátedra, 2014. 344 p.

CUNHA, Maria das Graças Campolina. Gameleira, Sertão Norte de Minas Gerais: um olhar feminino sobre o feminino camponês. 2013. 314 f. Tese (Doutorado em Geografia) Programa de Pós Graduação em Geografia, Universidade Federal de Uberlândia, 2013.

FARIA, Guélmer Júnior Almeida de; MACEDO, Luiz Antonio de Matos; PAULA, Andrea Maria Narciso Rocha de. "Do seu lugar para o lugar dos outros": a migração de mulheres e sua inserção no trabalho doméstico. ARGUMENTOS - Revista do Departamento de Ciências Sociais da Unimontes, v. 9, n. 8, p. 115-136, 2014. Disponível em: < http://www.cienciassociais.unimontes.br/arqu ivos/ed_09/08_Guelmer.pdf>.. Acesso em 18 jun. $20 \overline{18}$. 
FONSECA, Gildette Soares; GUIMARÃES, Rafael Lopes Nogueira; FERNANDES, Duval Magalhães. Norte de Minas: migrações intraestadual censo demográfico 2010. Revista Desenvolvimento Social, Edição Especial, p. 89-103, 2014.

GOMES, Nayhara Freitas Martins. A mobilidade socioespacial dos rurais e suas expressões citadinas: uma análise do município de Araponga, MG. 2015. 189f. 2015. Dissertação (Mestrado em Extensão Rural) - Universidade Federal de Viçosa, Viçosa, 2015.

HAESBAERT, Rogério. Da desterritorialização à multiterritorialidade. Anais do $X$ Encontro de Geógrafos da América Latina, Universidade de São Paulo, 2005.

HARTWIG, Marisa. Migração campo cidade: trajetórias de vida, trabalho e escolarização de jovens trabalhadores. In: I SEMINÁRIO INTERNACIONAL E I FÓRUM DE EDUCAÇÃO DO CAMPO DA REGIÃO SUL DO RS: CAMPO E CIDADE EM BUSCA DE CAMINHOS COMUNS, 2012, Pelotas/RS. Anais... UFSC. Disponível em: < http://coral.ufsm.br/sifedocregional/images/A nais/Eixo\%2001/Marisa\%20Hartwig.pdf>.

Acesso em 18 jun. 2018.

IBGE, Censo Demográfico. Censo Demográfico 2010: Nupcialidade, fecundidade e migraçãoResultados da amostra. Rio de Janeiro, 2010.

LOURO, Guacira Lopes. Gênero, sexualidade e educação: uma perspectiva pósestruturalista. 6. ed. Petrópolis, Rio de Janeiro: Vozes, 1997. 179 p.

MARQUES, Marta Inez Medeiros. O conceito de espaço rural em questão. Revista Terra Livre, v. 18, n. 19, p. 95-112, jul./dez. 2002. Disponível em: <https://www.agb.org.br/publicacoes/index.p hp/terralivre/article/view/160>. Acesso em 27 jun. 2018.

PAULA, Andréa Maria Narciso Rocha de. Integração dos Migrantes Rurais no mercado de trabalho em Montes Claros, Norte de Minas Gerais: "A Esperança de Melhoria de Vida". 2003.159 f. 2003. Dissertação (Dissertação de Mestrado) - Instituto de Geografia - Universidade Federal de Uberlândia - Uberlândia/Minas Gerais.
PAULA, Andréa Maria Narciso Rocha de. O espaço rural: representações socioespaciais do sujeito migrante no norte de Minas Gerais Brasil. In: Conflitos sociais na história contemporânea do Norte de Minas. SANTOS, Gilmar Ribeiro dos; PEREIRA, Laurindo Mékie (Org.). Montes Claros: Editora Unimontes, 2012. 251p.

PAULA, Andréa Maria Narciso Rocha de. Travessias... Movimentos migratórios em comunidades rurais no Norte de Minas Gerais. Revista VITAS - Visões Transdisciplinares sobre Ambiente e Sociedade, n. 4, 2012.

PNUD, Programa de las Naciones Unidas para el Desarrollo. Informe sobre Desarrollo

Humano 2016: Desarrollo humano para todas las personas. Nueva York, Estados Unidos, 2016. 286 p. Disponível em: <http://www.br.undp.org/content/brazil/pt/ho me/idh0/relatorios-de-desenvolvimentohumano/r dhs-globais.html>. Acesso em 14 mai. 2018.

ROSA, João Guimarães. Grande Sertão: Veredas. Rio de Janeiro: Nova Fronteira, 2006. 608 p.

SCOTT, Parry. Gênero e Geração em contextos rurais: algumas considerações. In: SCOTT, Parry; CORDEIRO, Rosineide; MENEZES, Marilda (org.). Gênero e geração em contextos rurais. Ilha de Santa Catarina: Editora Mulheres, 2010.

WOORTMANN, Ellen F. Da complementariedade à Dependência: espaço, tempo e gênero em comunidades "pesqueiras" do Nordeste. Revista Brasileira de Ciências Sociais, v. 7, n. 18, p. 41-61, 1992.

WOORTMANN, Ellen F. Prefácio. In: SCOTT, Parry; CORDEIRO, Rosineide; MENEZES, Marilda (org.). Gênero e geração em contextos rurais . Ilha de Santa Catarina: Editora Mulheres, 2010. 